\title{
EVALUATION OF THE SOIL ELASTIC MODULES BY MEANS OF BOX TESTS
}

The experimental measurements results of static and dynamic elastic modules $\left(E_{s}, E_{D}\right)$ and initial tangent modules $\left(G_{o}, E_{o}\right)$ of soils evaluated by means of box tests application techniques for calculation of these modules via static and dynamic loading half - space test means (SLT, DLT) and via shear wave velocity measurements tests are given. In the cross - hole method, body wave velocities are commonly evaluated from visual determinations of arriva timel of the waves at receivers. Additional time - determination techniques based on correlation and spectral analysis are discussed. The correlation technique is based on the cross - correlation function of waveforms recorded by two receivers. The spectral analysis technique is based on the phase of cross - energy spectral density function. The linear elastic and linear viscous - elastic behaviour of soils approach enables to measure soils damping parameters by mentioned box test means, too.

\section{Initial Tangent Modules $-E_{o}, G_{o}$}

Initial tangent modules (Richart, Hall, Woods [7]) of soils can be measured in the field or in the laboratory. If only low amplitude strains occur (strain less than 0.001 percent), the key soil parameters are the initial tangent modules $\left(E_{o}, G_{o}\right)$. The most direct field method and box test method for determining initial tangent modules is seismic testing. Shear and constrained modules are evaluated directly from shear $\left(v_{s}\right)$ and compression $\left(v_{p}\right)$ velocities, respectively, using the theory of elasticity.

In the Impact - seismic method (ISM), body waves velocities are commonly evaluated from visual determinations of the wave arrival time at receivers or by time - determination techniques based on correlation and spectral analysis (Bendat and Piersol [4]).

\subsection{Theoretical Studies}

The linear elastic and linear visco - elastic behaviour of soils, respectively, generally in the case of small vibration amplitudes transmitted by ground are determined in theoretical works (Benčat [3], Martinček [5] ). The visco - elastic model of simulation using complex modules $E_{o}, G_{o}, K_{o}$ offers a very good approach to the actual soil behaviour. The complex modules are given by the formulae

$$
\begin{aligned}
& E_{o}^{*}=E_{o}\left(1+i \delta_{E}\right), \\
& G_{o}^{*}=G_{o}\left(1+i \delta_{G}\right),
\end{aligned}
$$

where $E_{o}, G_{o}$ are real components of initial (seismic) complex modules, $(\mathrm{MPa}) ; \delta_{E}, \delta_{G}$ are imaginary components of initial complex modules and represent the viscous properties of soil media. The relationship between a logarithmic decrement ( $)$ ), damping parameters $\left(\delta_{E} \approx \delta_{G} \approx \delta\right)$ and a hysteretic damping ratio $(D)$ is approximately given by formula

$$
\vartheta \approx \pi \delta \approx 2 \pi \mathrm{D} .
$$

The determination of shear modulus $G_{o}$ given by Rayleigh's $\left(v_{R}\right)$ and shear $\left(v_{S}\right)$ wave velocities, respectively, has been the object of experimental box tests. For linearly elastic medium (with low damping, like most soils at small strains) the shear modulus is derived as follows

$$
G_{o}=v_{S}^{2} \rho,
$$

where $\rho$ is unit mass $\left(\mathrm{kgm}^{-3}\right), v_{S}$ is shear wave velocity $\left(\mathrm{ms}^{-1}\right)$. The resilient modulus $E_{o}$ is given by formula

$$
E_{o}=2(1+v) v_{S}^{2} \rho,
$$

where $v$ is Poisson's ratio.

\subsection{Measuring Procedure}

A special test facility was constructed for ISM tests in Laboratory Dept. of Structural Mechanics, University of Žilina. It incorporated a wooden box (Fig.1) with dimensions of $316 \times 290 \times$ $145 \mathrm{~cm}$ to examine the correlation between static, dynamic and

\footnotetext{
* Jan Bencat ${ }^{1}$, Milan Cibulka ${ }^{2}$, Milan Hrvol $^{3}$

${ }^{1}$ Jan Bencat, Department of Structural Mechanics, Civil Engineering Faculty, University of Zilina, Slovakia, E-mail: jan.bencat@fstav.uniza.sk

${ }^{2}$ Milan Cibulka, CISS CITY, s.r.o., Zilina, Slovakia

${ }^{3}$ Milan Hrvol, STAVBAU,s.r.o., Zilina, Slovakia
} 
seismic modules of the subballast and subgrade under simulated field conditions. The construction of the box, static loading test $(S L T)$ and dynamic loading (impact) test (DLT) are fully described in Sec. 2.1

It is common practice in the seismic methods (ISM) to use a line source - receiver array with one or two receivers located at a distance $1(m)$ from the source (Fig. 1).

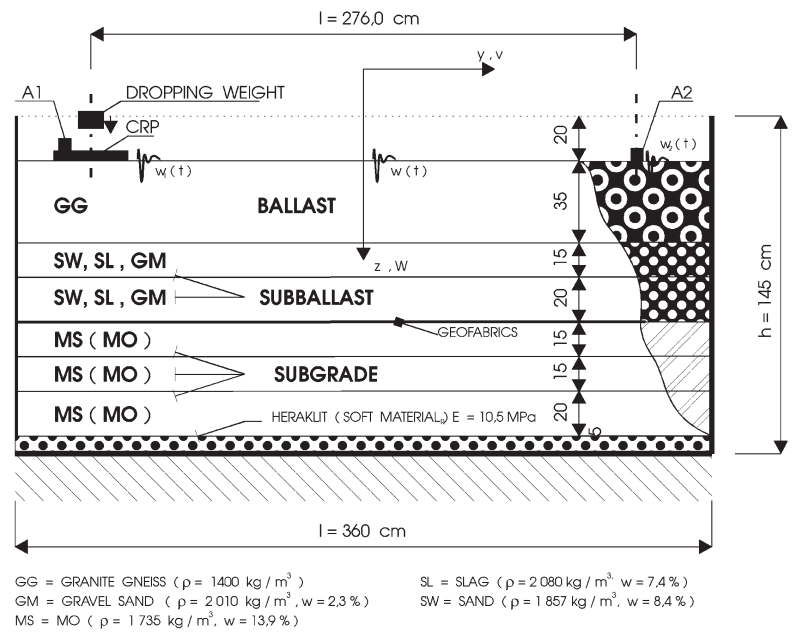

Fig. 1 Box Test Layout - Site View with Cutway Section

Propagation of body waves generated by the source is monitored with receivers $(A 1, A 2)$ at the same depth as the source. The traditional approach used in the box tests to determine shear wave velocity $\left(v_{s}\right)$ is based on identifying the time interval of the wave travelling between the first $(A 1)$ and second $(A 2)$ receivers. Once these times are determined, velocities are calculated via dividing distance $(l)$ by appropriate times. Wave velocities determined by source to receiver measurements are termed the direct velocities method. Other techniques based on correlation and spectral analysis theories can be employed to determine body wave velocities in the ISM test (as well as other seismic tests like crosshole and downhole tests). This approach offers benefits in two areas. First, interval velocities have fewer potential errors than direct velocities (Stoke [9]). Second, the techniques can be fully automated. Furthermore, the retrieval of additional information such as strain rate effects and material damping is possible with spectral analysis. The first of this time - determination techniques is based on the cross - correlation function of waves travelling by two receivers. The cross - correlation $R_{x y}(\tau)$ of two functions $w_{1}(t)$ and $w_{2}(t)$ is given by the integral

$$
R_{x y}(\tau)=\int_{-\infty}^{\infty} w_{1}(t) w_{2}(t+\tau) d t
$$

where $w_{1}(t)$ and $w_{2}(t)$ are time histories of the motion of the wave passing by the first and second receivers (waveforms); $\tau$ is the time delay and $t$ is the variable of integration.
The two waveforms to be correlated are the same but one lags the other a time $t^{*}$, then the cross - correlation function will exhibit a maximum at $\tau$ equal $t^{*}$. If this two shifted but otherwise identical waveforms represent the waves recorded at two receivers, the time $t^{*}$ will correspond to the time at which the peak of the cross - correlation function occurs and will represent the travel time of the wave between the receivers. If the distance between receivers is divided by time, the $v_{s}$ velocity will be obtained. Another way to calculate wave velocities is based on the cross - energy spectral density function of the waveforms obtained at two different receivers $(A 1, A 2)$. The cross - spectrum $G_{x y}(f)$, of two functions, $w_{1}(t)$ and $w_{2}(t)$, is

$$
G_{x y}(f)=G(f) \overline{H(f)},
$$

where $G(f)$ and $H(f)$ are the Fourier transforms of $w_{1}(t)$ and $w_{2}(t)$, respectively, $f$ is frequency in $\mathrm{Hz}$ and " " indicates the complex conjugate.

Assume that the functions $w_{1}(t)$ and $w_{2}(t)$ are time records at the two receivers, for each frequency, the phase of the cross energy spectrum of $w_{1}(t)$ and $w_{2}(t)$ will give the phase difference of the corresponding harmonic. Since the time period of that harmonic is known $(T=1 / f)$, a travel time between receivers can be obtained for each frequency by

$$
t(f)=\Theta_{x y}(f) / 2 \pi f,
$$

where $\Theta_{x y}(f)$ is the phase (in radians) of the cross - energy spectrum. The distance between receivers $(l)$ is the known parameter. Therefore, the apparent velocity is

$$
v(t)=1 / t(f)
$$

\subsection{Case Studies}

The records obtained from shear wave velocity measurements by $I S M$ test at a box soil media are analyzed as an application of the travel time determinations explained above.

Details of the box set - up and equipment used can be found in reference Benčat [1]. The records obtained from shear wave velocity measurements by ISM test of the box soil media are analyzed as an application of the travel time determinations explained above. Details of the box set - up and equipment used can be found in reference Benčat [1]. The time records of shear wave motion obtained with two vertical acceleration transducers located at points $A 1$ and $A 2$ are presented in Figs. 2a and 2b. The time interval obtained from the first arrivals of the shear wave is $t=29.29 \mathrm{msec}$. This corresponds to a shear wave velocity $v_{s}=94.23 \mathrm{~m} / \mathrm{s}$ and modulus for subgrade material $\left(M S, \rho=1735 \mathrm{~kg} / \mathrm{m}^{3}, w=13.9 \%\right.$ $v=0.3) E_{o}=40.05 \mathrm{MPa}$.

The cross - correlation function of the two time records is presented in Fig. 2c. The maximum value of this function occurs at time $t^{*}=29.40 \mathrm{~m} / \mathrm{s}$. The shear wave velocity calculated with 

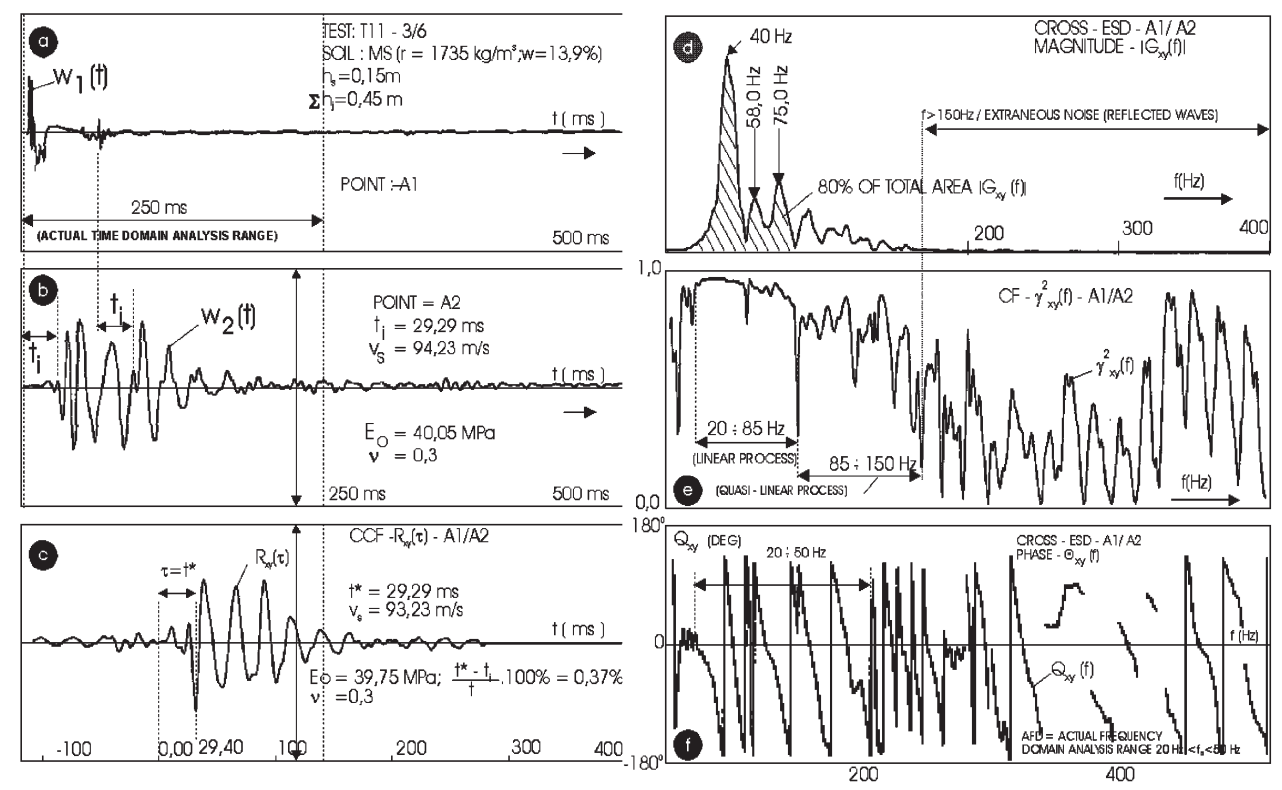

Fig. 2 Determination of shear wave velocity of Mo at level $\mathrm{h} 3=45 \mathrm{~cm}$

a) Time history at the first accelerometer; b) Time history at the second accelerometer; c) Cross correlation function; d) Magnitude of cross energy spectral density; e) Coherence function; f) Phase of cross energy spectral density

this time is $v_{s}=93.87 \mathrm{~m} / \mathrm{s}$ and modulus $E_{o}=39.75 \mathrm{MPa}$. The phase of the cross - spectrum is shown in Fig. 2f, along with the coherence function in Fig. 2e and energy cross - spectrum in Fig. $2 d$. For a signal with no background noise, the coherence function $\gamma_{x y}{ }^{2}(f)$ should have a value of one at any frequency if the system is considered linear. Comparison between mean value of the statistical value collection of all corresponding static and seismic resilient modules $E_{o} / E_{s}$ at layer of soil under investigation (MS, test $T$ 113/6) gives ratio: $E_{o} / E_{s}=2.38$. There were also evaluated ratios $E_{o} / E_{s}$ and $E_{D} / E_{s}$ for each layer of the soils creating a corresponding combination of the subballast and subgrade in the box using the procedure described above.and in the folloving sections.

\section{Static and Dynamic Modules - ES ,ED}

Theory of an elastic half - space (Timoshenko and Goodier [10], Johnson [6]) provides formulation for the evaluation of elastic modules $E_{s}, E_{D}$. Pushing the rigid circular plate into the elastic half - space with uniform pressure (Hertz pressure) enables to develop the relationship for the evaluation of the resilient modulus $E_{s}=$ $=E_{s}(r, w, v)$ as follows:

$$
E_{s}=\pi / 2\left(1-v^{2}\right)(r \cdot p, w)
$$

where: $r$ is the radius of a rigid circular plate $(\mathrm{mm}), p(\mathrm{MPa})$ is static or dynamic pressure at the contact area of the rigid circular plate and the half - space, $w$ is uniform normal displacement of the contact area $(\mathrm{mm}), E_{s}(\mathrm{MPa})$ is resilient modulus and is Poisson's ratio.
Eq.(2.1) is utilized in both the static and the dynamic experimental tests for the evaluation of static and dynamic resilient modules of soils in situ or by means of the box test. Based on the examination of the available models of the track substructure and considering of its desired features, the theoretical model based on an elastic approach provides satisfactory results for practical aims. To introduce a dynamic loading test ( $D L T$ ) for in situ measurement of the resilient modules it was necessary to find the relationship between static $\left(E_{s}\right)$ and dynamic $\left(E_{D}\right)$ modules of the soils and substitute materials (e.g. granulated slag) which are used as in track subballast. Up to now, principles of the method of sleeper subgrade construction arrangement has been used at ŽSR (Slovak Railways) using modulus Es for each layer. To avoid the expensive experiments in situ both the static and the dynamic tests of soil parameters, the box tests were carried out in the laboratory. Several tests have been validated by comparison with field measurements from a test track, too. A special test facility was constructed for this purpose. It incorporated a wooden box (Fig. 3) with dimensions of $316 \times 290 \times 145(\mathrm{~cm})$, to examine the correlation between static and dynamic resilient modules of the subbalast and subgrade under simulated field conditions.

Fig. 3 also shows numbered layers of the subgrade and subbalast and provides the description of the construction of the box and steel frame of the hydro mechanical equipment for the static loading test. At the contact areas both the bottom and side walls of the box were covered with soft composite material of $5.0 \mathrm{~cm}$ thickness and with modulus $E_{s}=10.5 \mathrm{MPa}$. Before starting the static test, the optimal regime of the electrodynamics plate vibrator acting to achieve an optimal degree of the soil compacting according to Proctor standard test (P.S.T.). For each layer after 


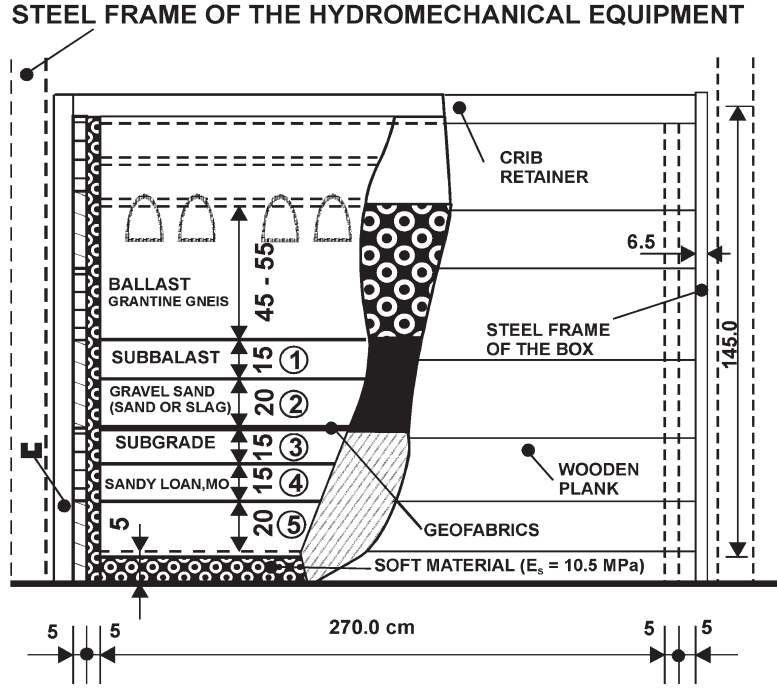

Fig. 3 Box test layout - Side view with cutway section

compacting specimens for standard laboratory test of the soil geotechnical properties (e. g. grain characteristics, specific gravity $G_{s}$, mass density $(\rho)$, moisture $(w)$ void ratio $(e)$, compaction level, degree of saturation $\left(S_{R}\right)$, Poisson's ratio $(v)$, etc.) were taken.

For cohesionless soils the optimal degree of compacting was expressed by volume mass with the application of TROXLER device (radiometric probe half - space JGP 104). Fig. 5 shows the location of the points $\left(G_{1}, G_{3}\right)$ for taking specimens of soil at each layer of the substructure. The subgrade was successively created by three layers of $20.0+15.0+15.0=50.0 \mathrm{~cm}$ of the cohesive soils and the subballast was created by the combination of the cohesionless soils imposed on the subgrade either with geofabrics or without the geofabrics. During the test the properties of the tested soils were approximately constant. Six combinations of soils and substitute materials which created the layered substructure were carried out. For each combination of soils the subgrade was made as a sandy loam $(M S)$ with parameters $\rho=1735.0 \mathrm{~kg} / \mathrm{m}^{3}, w_{O P T}=13.9 \%$. The layers of the subballast were successively created by gravel sand, sand and slag. The layers of the subballast in each test have thickness of $20.0+15.0=35.0 \mathrm{~cm}$.

\subsection{Static Loading Test (SLT)}

The static resilient modulus $E_{s}(\mathrm{MPa})$ of the tested soils was evaluated by measuring the rigid circular plate vertical displacement $w(\mathrm{~mm})$ due to hydro mechanical equipment. The contact area of the plate for each test was $A=1000.0 \mathrm{~cm}^{2}$. Fig. 4 shows the location of points $B 1 \ldots B 15$ for the SLT. The resulting vertical displacement $w$ of the circular plate for each test was obtained as an average value of the displacement values measured in the points $S 1, S 2$ and $S 3$ which were situated on the top of the plate. The vertical displacements were measured by inductive displacement transducers which were connected to the signal amplifier and via computer recorded and printed. Fig. 5 shows the interpretation of

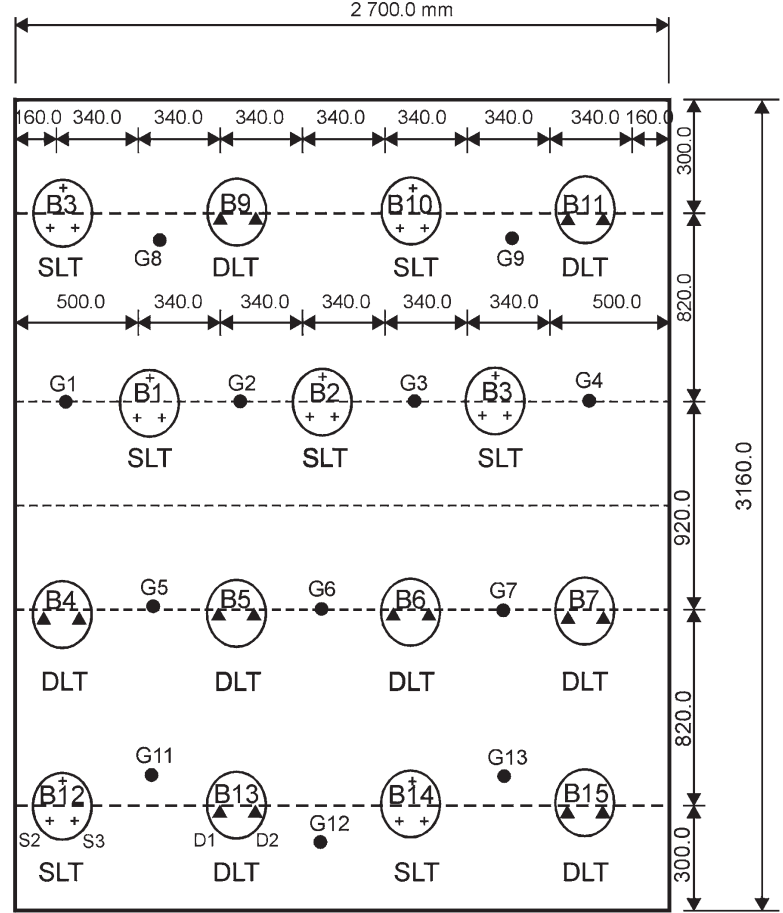

B1 ...B15 POINTS FOR LOADING TEST

G1 ...G3 POINTS FOR TAKING SPECIMENTS (•)

SLT $=$ STATIC LOADING TEST, S1,S2,S3 . . MEASURED POINTS (+)

DLT = DYNAMIC LOADING TEST, D1,D2 . . MEASURED POINTS $(\boldsymbol{\Lambda})$

Fig. 4 Box test layout - Plan view with position of measured points

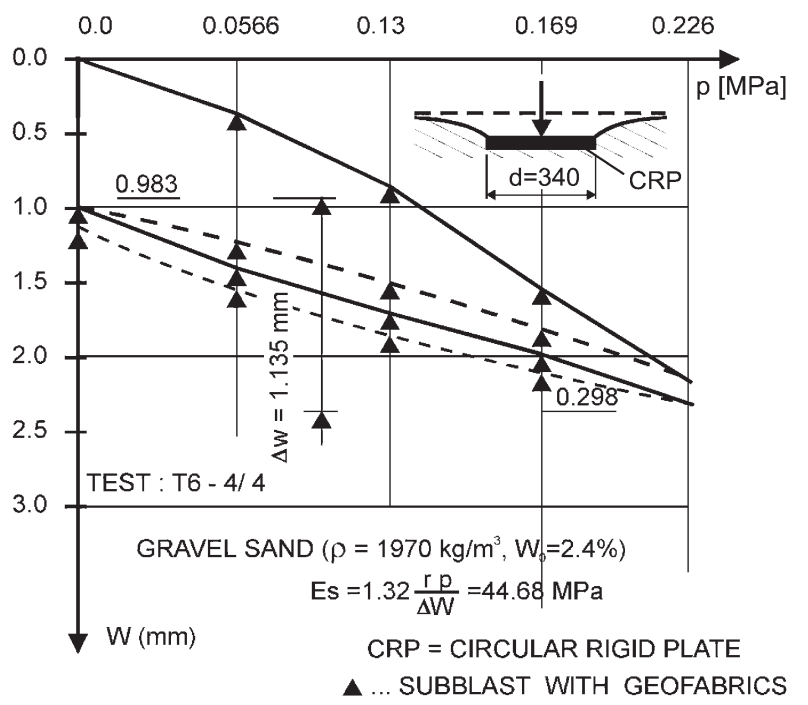

Fig. 5 Displacement time history of the static loading test

the displacement time history of the typical static loading test (T64/4).

The resilient modules $E_{s}$ were calculated according to Eq. (2.1) where $w=\Delta w$ is the measured value of the vertical displace- 
ment for the second cycle of the SLT due to pressure $p=0.22$ $\mathrm{MPa}$. This approach is sufficient because after a number of load repetitions, the soils behave nearly elastically as confirmed by the preceding tests. Then the resilient modulus $E_{s}$ can be defined as a repeated stress deviator (Seed [8]) divided by the recoverable strain and it does not usually change significantly after a large number of cycles.

\subsection{Dynamic Loading Test (DLT)}

Dynamic resilient modulus $E_{D}(\mathrm{MPa})$ was evaluated in the same way as a static modulus $E_{s}$, but the dynamic load was performed by impact loading test device, Fig. 6 . This device consists of the circular rigid plate (1) with the contact area $A=1000.0 \mathrm{~cm}^{2}$, dropping weight (2) with the mass $Q=12.5 \mathrm{~kg}$, indention for setting the height of the weight (3), springs (4), plunger (5) guide rod (6) casing (7) and safety pin (8). $D l$ and $D 2$ are points where the dynamic vertical displacements were measured by inductive displacement transducers. The measuring of dynamic deflections was performed by the same set of the apparatus as in the case of static tests. Fig. 4 shows location of the points where DLTs were performed. In each dynamic test 6 impacts in the measured spot were introduced by dropping weight from the constant height $h$. The height $\mathrm{h}$ was set experimentally to achieve the constant area impact stress $p=0.22 \mathrm{MPa}$. In this case the dynamic modules were calculated according to Eq.(2.1), where $\mathrm{w}$ is the mean displacement value, obtained from the measurements at points $D 1$ and $D 2$ situated on the top of the circular plate (from the 5 last values of the 6 performed impacts). Fig. 7 shows typical displacement time history of the dynamic deflection during the impact caused by dropping weight $Q$.

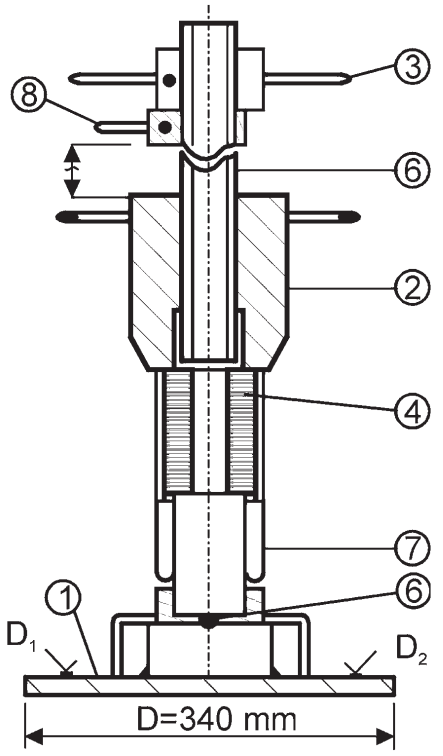

Fig. 6 Dynamic loading test device

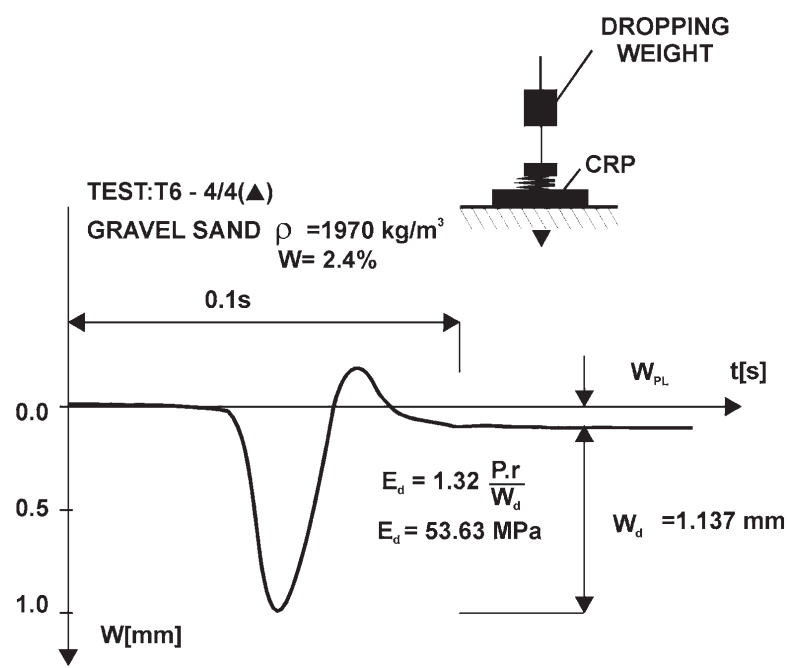

Fig. 7 Displacement time history of the dynamic loading test

\subsection{Experimental Results}

Seven static and eight dynamic loading tests were performed in each layer of the soils creating a corresponding combination of the subballast and subgrade in the box. Finally, we obtained 35 values of the $E_{s}$ and 40 values of the $E_{D}$, for the soil combinations in each box test. There were carried out 6 combinations of soils with and without geofabrics at the top of the subgrade. Fig. 8 shows the ratio between dynamic and static $\left(E_{D} / E_{s}\right)$ and initial tangent and static resilient modules $\left(E_{o} / E_{s}\right)$ for individual soils in the box test combination, (Benčat et.al.[2], Benčat[11]). Fig. 8 also

$$
\left(E_{i} / E_{S}\right)
$$

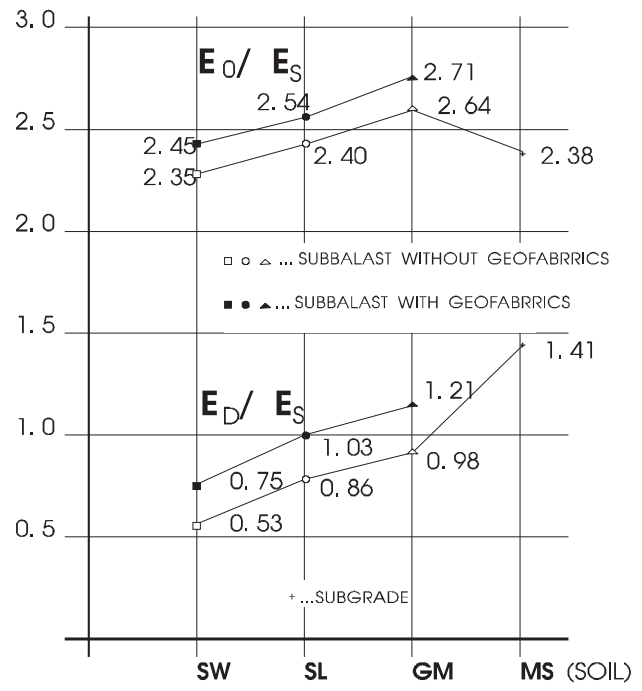

Fig. 8 Ratio $E_{o} / E_{S}$ and $E_{D} / E_{s}$ for individual soils in the box test combination 
shows the interpretation of the ratio $E_{D} / E_{S}$, which was calculated as a mean value of the statistical value collection of all corresponding tests. The correlation coefficient $\mathrm{k}$ varied from 0.85 to 0.92 .

\section{Conclusions}

The box test results confirmed the results obtained from in situ tests with the same experimental set - up apparatus. The advantages of the box tests are in the constant conditions during the test performance, possibility to change combinations of soils creating a railway substructure and in lower expenses in performing the study of the track structure material properties. The results will be utilized in performing $D L T$ in the evaluation of bearing capacity of substructure layers in present and newly built Slovak Railways networks. The technique to determine travel time of body waves in geotechnical seismic testing has received little attention. Travel time is required to calculate shear wave velocities from which initial tangent modules $\left(G_{o}, E_{o}\right)$ are determined. With the use of portable signal processing equipment and other techniques for travel time determination, such as correlation and spectral analysis, can be effectively implemented in the field tests, too.

Acknowledgements. This work has been supported by the Scientific Grant Agency (Ministry of Education of the Slovak Republic), Grant Contract: 1/3360/06 and University of Žilina Institutional Grant Contract: SvF/002/302/2006.

[1] BENCAT, J.: Research in Railway Structure Dynamics (in Slovak), Research Report III-4-6/03.03, Vol. II., University of Zilina, Dept. of Structural mechanics, Zilina, 1989.

[2] BENCAT, J. et al.: Dynamics, Diagnostisc and Reliability of Structures (in Slovak), Report No. SvF - A - 4/91, University of Zilina, Civil Eng. Faculty, Zilina, 1991.

[3] BENCAT, J.: Verification by Comparison Between Static and Dynamic Engineering Soil Parameters Evaluated by Means of Box Tests, Proc. of Conf. on Recent Advanced in Geotechnical Earthquake Engineering and Soil Dynamics, UMR, Rolla, Missouri, 1991, Vol. III., pp. 1901-1903.

[4] BENDAT, J. S., PIERSOL, A. G.: Engineering Applications of Correlation and Spectral Analysis, John Wiley \& Sons, New York, 1980

[5] MARTINCEK, G.: Dynamics of Pavement Structures, E\&FN SPON, Chapman\&Hall, Boundary Row, London 1994.

[6] JOHNSON, K. L.: Contact Mechanics, Cambridge University Press, Cambridge, New York, Sydney, 1985.

[7] RICHARD, E., HALL, J. R., WOODS, R. D.: Vibrations of Soils and Foundations, Prentice - Hall Inc., Englewood Cliffs, New Jersey, N. J., 1970.

[8] SEED, M. B., et al.: Prediction of Pavement Deflections from Laboratory Repeated Load Test, Report No. TE-65-6, Soil Mechanics and Bituminous Materials Research Laboratory, University of California, Berkley, 1965.

[9] STOKE, K. H., HOAR, R. J.: Variables Affecting In Situ Seismic Measurement, Proc. of Conference on Earthquake Eng. and Soil Dynamics, ASCE, Pasadena, California, Vol. II/1978.

[10] TIMOSHENKO, S. P., GOODIER, J. N.: Theory of Elasticity, $3^{\text {rd }}$ Edn. New York, London , McGraw-Hill, 1951.

[11] BENCAT, J.: Evaluation of the Soil Initial Tangent Modules $\left(E_{o}, G_{o}\right)$ by Shear Wave Propagation Method, Proc. of the Tenth International Conference on Civil, Structural and Environmental Engineering Computing, B.H.V. Topping, (Editor), Civil-Comp Press, Stirling, United Kingdom, p. 266, 2005. 